\title{
GM1 Ganglioside Improves Dopaminergic Markers of Rat Mesencephalic Cultures Treated with MPP+
}

\author{
A. Dalia, ${ }^{1}$ N. H. Neff, ${ }^{1,3}$ and M. Hadjiconstantinou ${ }^{1,2,3}$ \\ Departments of ${ }^{1}$ Pharmacology and ${ }^{2}$ Psychiatry and the ${ }^{3}$ Neuroscience Program, The Ohio State University College of \\ Medicine, Columbus, Ohio 43210
}

\begin{abstract}
Rat embryonic mesencephalic cultures were employed to evaluate the consequences of adding GM1 ganglioside to cultures lesioned with the selective neurotoxin 1-methyl-4phenylpyridinium $\left(\mathrm{MPP}^{+}\right)$. MPP ${ }^{+}$reduced dopamine and DOPAC content, dopamine uptake, aromatic L-amino acid decarboxylase activity, and the number of tyrosine hydroxylase-immunopositive neurons. The immunopositive neurons that remained were aberrant. All of these parameters were partially restored by adding GM1 ganglioside to the cultures. The response to GM1 was not altered by prior treatment of the cultures with cytosine $\beta$-D-arabinofuranoside to reduce the number of glial cells. Dopamine uptake activity restored by GM1 was lost if GM1 was removed from the culture.
\end{abstract}

[Key words: GM1 ganglioside, mesencephalic cultures, dopaminergic neurons, neurotrophic activity, MPP+ (1-methyl-4-phenylpyridinium), Parkinson's disease]

There is now substantial evidence that GMl ganglioside (II ${ }^{3} \mathrm{NeuAc}-\mathrm{GgOse}_{4} \mathrm{Cer}$ ) treatment improves the outcome of a variety of CNS insults when evaluated using in vivo or in vitro models (Ledeen, 1984). The mechanism(s) involved is unclear, though there is evidence that GM1 inserts into cell membranes (Toffano ct al., 1980; Ghidoni et al., 1989) and may prevent $\mathrm{Ca}^{2+}$ influx from reaching toxic concentrations within cells (Vaccarino et al., 1987; Favaron et al., 1988; de Erausquin et al., 1990) and/or may support the activity of endogenous neurotrophic substances (Hakomori et al., 1990).

$\mathrm{MPP}^{+}$(1-methyl-4-phenylpyridinium ion), formed in glial cells by monoamine oxidase $B$, is the neurotoxic product of MPTP (1-methyl-4-phenyl-1,2,3,6-tetrahydropyridine) metabolism in brain (Heikkila et al., 1984a,b, 1985; Nicklas et al., 1985). MPP+ selectively concentrates in dopaminergic neurons (Javitch et al., 1985), where it disrupts mitochondrial energy metabolism (Singer et al., 1988), resulting in neuronal death. MPTP has been used to induce model parkinsonism in animals. We have previously demonstrated that GM1 can facilitate the recovery of dopaminergic neurochemical, morphological, and behavioral markers in rodents treated with MPTP (Hadjiconstantinou et al., 1986, 1989a,b; Hadjiconstantinou and Neff,

Received Nov. 11, 1992; revised Feb. 4, 1993; accepted Feb. 8, 1993.

This work was supported, in part, by grants from FIDIA Research Laboratories and the Parkinson's Disease Foundation, and A.D. was supported by NS-07291.

Correspondence should be addressed to Maria Hadjiconstantinou, M.D., Department of Pharmacology, The Ohio State University College of Medicine, 5198 Graves, 333 West 10th Avenue, Columbus, OH 43210-1239.

Copyright (C) 1993 Society for Neuroscience $0270-6474 / 93 / 133104-08 \$ 05.00 / 0$
1988, 1990; Weihmuller et al., 1988, 1989). These studies were recently extended to primates (Schneider et al., 1992). In this report, we show that GMl can apparently rescue dopaminergic neurons in embryonic mesencephalic cultures treated with $\mathrm{MPP}^{+}$.

\section{Materials and Methods}

Preparation of mesencephalic cultures. Timed-pregnant Sprague-Dawley rats were purchased from Zivic-Miller Labs (Zelienople, PA). Mesencephalic cultures were prepared from embryonic day 15 (E15) embryos as described by Friedman and Mytilineou (1987). Pooled ventral mesencephalic tissues were mechanically dissociated and plated at a density of $1-1.5 \times 10^{6}$ cells in $35 \mathrm{~mm}$ plastic dishes that were precoated with poly-D-lysine. The number of viable cells added to a dish was determined from trypan blue exclusion and counting in a hemocytameter chamber. Culture medium consisted of Eagle's minimal essential medium supplemented with glucose, $30 \mathrm{~mm}$; L-glutamine, $2 \mathrm{~mm}$; fetal calf serum, $5 \%$; horse serum, $5 \%$; penicillin, $100 \mathrm{U} / \mathrm{ml}$; and streptomycin, $100 \mu \mathrm{g} / \mathrm{ml}$. Cultures were incubated at $37^{\circ} \mathrm{C}$ in an atmosphere of $5 \% \mathrm{CO}_{2}$ in air with $100 \%$ relative humidity. The medium was changed every third day. For morphological studies cells were grown on $22 \times$ $22 \mathrm{~mm}$ glass coverslips. The morphological appearance of the cells was followed with a phase-contrast microscope.

Treatments. Initial studies were performed to determine the concentration and duration of exposure to MPP+ that would reduce dopamine (DA) uptake in the cultures by about $50 \%$. Based on these studies a concentration of $3 \mu \mathrm{M} \mathrm{MPP}+$ was added on the fourth day in culture and removed $24 \mathrm{hr}$ later. At this concentration of $\mathrm{MPP}^{+}$there were no general toxic effects as evidenced by no detectable change of dish protein content and the morphological appearance of cells with a phase-contrast microscope.

GM1 ganglioside (generously supplied by Dr. Gino Toffano, FIDIA Research Laboratories) was added on day 5 in culture immediately after removing $\mathrm{MPP}^{+}$. Concentration-response and time-response studies were performed to establish the effectiveness of GM1. For most studies we treated the cultures for $7 \mathrm{~d}$ (day 12 in culture) with $0.5 \mu \mathrm{M} \mathrm{GM1}$ unless otherwise indicated. GM1 had no discernable toxic effects on the cultures and did not alter the protein content of washed cultures. In addition, GM1 had no effect on DA uptake or aromatic L-amino acid decarboxylase (AAAD) activity when added to samples during an assay procedure.

For some studies monoclonal IgM anti-GM1 antibodies (generously provided by Dr. Norman Latov, Columbia University), diluted 1:100, or the B subunit of cholera toxin $(5 \mu \mathrm{g} / \mathrm{ml})$ (List Biological Laboratories, Campbell, CA), which selectively binds to GM1 (Fishman, 1986), was added to control and $\mathrm{MPP}^{+}$-treated cultures, either alone or together with GM1.

The influence of glial cells on the response of the dopaminergic neurons to GMI was evaluated by treating the cultures with cytosine $\beta$-D-arabinofuranoside (Ara-C; Sigma, St Louis, MO), $1.25 \mu \mathrm{M}$ on day 3 in culture for $24 \mathrm{hr}$. The cultures were washed on day 4 and MPP ${ }^{+}$ added for $24 \mathrm{hr}$ as described above.

$D A$ uptake estimation. Cultures were washed with $37^{\circ} \mathrm{C}$ phosphatebuffered saline (PBS) containing glucose, $5 \mathrm{~mm} ; \mathrm{CaCl}_{2}, 1 \mathrm{~mm} ; \mathrm{MgSO}_{4}$, $1 \mathrm{~mm}$; ascorbic acid, $0.1 \mathrm{~mm}$; and pargyline, $0.1 \mathrm{~mm}$. They were preincubated at $37^{\circ} \mathrm{C}$ for $5 \mathrm{~min}$, and then ${ }^{3} \mathrm{H}$-DA (dihydroxyphenylethylamine 3,4-[7-3 H]; New England Nuclear, Boston, MA), diluted with nonradiolabeled DA to a final concentration of $25 \mathrm{nM}$, was added and 


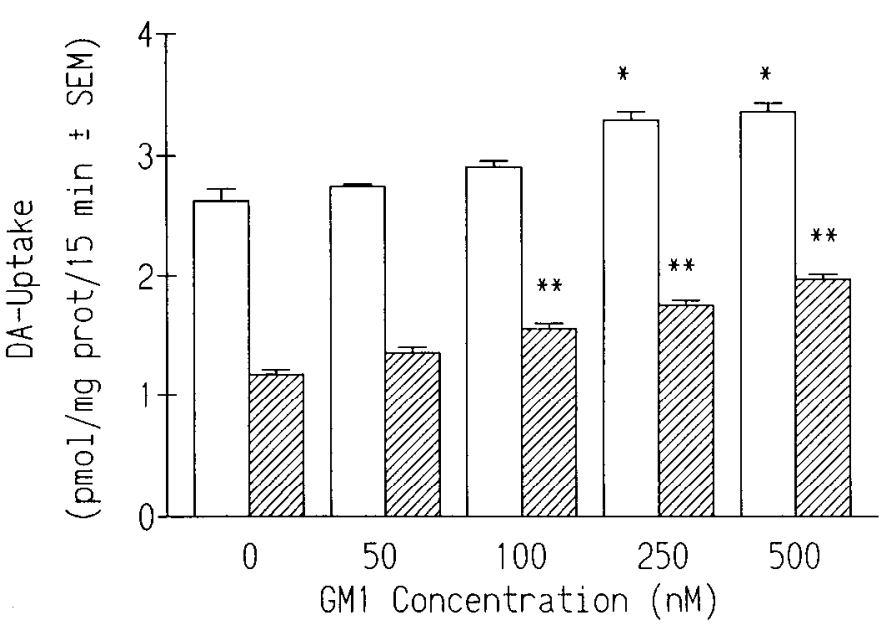

Figure 1. DA uptake by rat E15 mesencephalic cultures treated with $\mathrm{MPP}^{+}$and GM1 ganglioside. After $4 \mathrm{~d}$ in culture, MPP ${ }^{+}, 3 \mu \mathrm{M}$, was added for $24 \mathrm{hr}$. Then GM1 was added to the MPP+-treated cultures (hatched bars) and to comparison normal cultures (open bars), and DA uptake was assayed on day 12 in culture. Data are presented as the mean \pm SEM for $10-15$ dishes. ${ }^{*}, p<0.05$ compared with control untreated cultures. ${ }^{* *}, p<0.05$ compared with cultures treated with $\mathrm{MPP}^{+}$alone.

the incubation continued for $15 \mathrm{~min}$. Uptake was terminated by removing the medium and washing the cultures three times with ice-cold PBS solution described previously. ${ }^{3} \mathrm{H}-\mathrm{DA}$ was extracted from the cultures by adding two separate $0.5 \mathrm{ml}$ portions of a solution of $0.4 \mathrm{M}$ $\mathrm{HClO}_{4}$ and absolute ethanol (3:1 v/v) and scraping the dishes with a rubber policeman. The extract was sonicated and centrifuged, and a portion of the supernatant was counted for radioactivity. Nonspecific DA uptake was estimated in the presence of $5 \mu \mathrm{M}$ benztropine. To exclude the possible interference of uptake by serotonergic or noradrenergic neurons fluoxetine, $1 \mu \mathrm{M}$, and desipramine, $5 \mu \mathrm{M}$, respectively, were included in the incubation medium (Prochiantz et al., 1979). Protein was estimated by the method of Lowry et al. (1951).

$D A$ and DOPAC estimation. DA and DOP $\triangle$ C content in the cultures was established using HPLC with an electrochemical detector. In brief, the medium was removed and the dishes washed with the PBS solution described previously. Then the cells were removed from the dishes with $200 \mu \mathrm{l}$ of $\mathrm{HClO}_{4}, 0.5 \mathrm{M}$, containing $0.002 \%$ ascorbic acid. The mixture was homogenized and centrifuged, and $100 \mu \mathrm{l}$ of the supernatant was injected onto our HPLC system (Cohen et al., 1983).

$A A A D$ estimation. After washing with the PBS solution, cells were scraped from the dishes and homogenized with $130 \mu \mathrm{l}$ of ice-cold sucrose, $0.25 \mathrm{~m}$. The homogenate, $30 \mu \mathrm{l}$, was incubated in $400 \mu \mathrm{l}$ of a solution containing sodium phosphate buffer, $50 \mathrm{mM}, \mathrm{pH} 7.2$; L-dopa, $0.5 \mathrm{~mm}$ (D-dopa for estimation of blank values); ascorbic acid, $0.17 \mathrm{~mm}$; pyridoxal 5-phosphate, $0.01 \mathrm{~mm}$; pargyline, $0.1 \mathrm{~mm}$; 2-mercaptoethanol, $1 \mathrm{~mm}$; and EDTA, $0.1 \mathrm{~mm}$. Incubations were performed at $37^{\circ} \mathrm{C}$ for 20 min and the reaction was stopped by adding $80 \mu \mathrm{l}$ of icc-cold $\mathrm{HClO}_{4}$ $0.5 \mathrm{M}$, containing $10 \mathrm{pmol}$ of 3,4-dihydroxybenzylamine as an internal standard. The mixture was transferred to a small conical polypropylene test tube containing about $20 \mathrm{mg}$ of alumina, and catechol compounds were extracted and assayed by HPLC with electrochemical detection as described previously (Hadjiconstantinou et al., 1988).

Tyrosine hydroxylase immunohistochemistry. A method described by Beck et al. (1991) was used for the immunohistochemical studies. Briefly, cultures were washed with the PBS solution and fixed with formaldehyde, $4 \%$, for $30 \mathrm{~min}$. After washing again they were incubated for $24 \mathrm{hr}$ with a monoclonal mouse anti-tyrosine hydroxylase (TH) antibody (LNC 1, generously provided by Dr. Gregory Kapatos, Wayne State University) diluted 1:1000 in PBS containing bovine serum albumin, $2 \%$; Triton $X-100,0.2 \%$; sodium azide, $0.02 \%$; and goat serum, $1 \%$. Following washing with PBS, cultures were incubated with goat antimouse IgG $+\mathrm{A}+\mathrm{M}(\mathrm{H}+\mathrm{L})$ diluted 1:100 (Zymed, San Francisco, CA) for $2 \mathrm{hr}$. After washing again, cultures were incubated for $2 \mathrm{hr}$ with monoclonal mouse peroxidase-antiperoxidase complex (Zymed) diluted 1:100. Peroxidase was visualized by incubation with a solution of

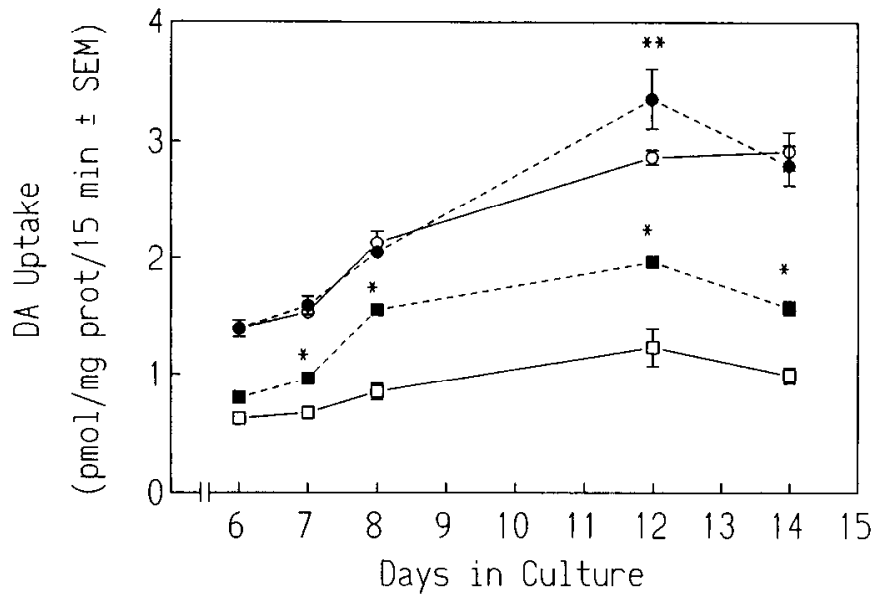

Figure 2. DA uptake by rat E15 mesencephalic cultures with time following $\mathrm{MPP}^{+}$or after $\mathrm{MPP}^{+}$plus GM1. Cultures were treated with $\mathrm{MPP}^{+}$as in Figure 1, and GM1, 0.5 $\mu \mathrm{M}$, was added and the incubation continued. Data are presented as the mean \pm SEM for control (open circles), control treated with GM1 (solid circles), MPP+ (open squares), and MPP + treated with GMI (solid squares). Data are presented as mean \pm SEM for $5-12$ dishes. ${ }^{*}, p<0.05$ compared with $\mathrm{MPP}^{+}$alone. ${ }^{* *}, p<0.05$ compared with control.

diaminobenzidine, $1 \mathrm{mg} / \mathrm{ml}$, and $0.015 \%$ hydrogen peroxide in PBS. TH-immunopositive cells were visualized with a Leitz Orthoplan 2 microscope coupled to a Dage MTI CCD72 camera and projected onto a Sony Trinitron super fine pitch monitor PVN 1343MD. Images of the cultures were made with a Sony video printer UP 3000 . The number of TH-immunopositive cells, the number of primary and secondary processes, the length of primary processes, and the soma perimeter were established with a computerized image analysis system.

Statistical analysis. Data were evaluated by analysis of variance followed by comparison of group differences with a Newman-Keuls test.

\section{Results}

Treating E15 mesencephalic cultures with the dopaminergic neurotoxin $\mathrm{MPP}^{+}, 3 \mu \mathrm{M}$, for $24 \mathrm{hr}$ on day 4 in culture, decreased all of the dopaminergic markers evaluated by $40-60 \%$ (see figures and tables). The loss of dopaminergic markers appears to be rather selective for DA-containing neurons as there was no detectable loss of protein from the cultures and there were no striking changes of cell morphology except for the TH-immunopositive cells.

GM1 treatment enhanced DA uptake in MPP+--lesioned cultures in a time- and concentration-dependent manner (Figs. 1, 2). The response appeared maximal at a concentration of about $0.5 \mu \mathrm{M}$ GM1. Enhanced DA uptake was evident as early as $2 \mathrm{~d}$ after adding GM1 to the MPP+-lesioned cultures and reached a maximum about $7 \mathrm{~d}$ later. When control mesencephalic cultures were incubated with GM1, there was a small but significant increase of DA uptake (Figs. 1, 2) when studied $7 \mathrm{~d}$ after initiating the treatment, day 12 in culture, but not at other days. The response of the $\mathrm{MPP}^{+}$-treated cultures to GM1 was maintaincd as long as the compound was present in the medium. DA uptake decreased after removing GM1 to values found for untreated $\mathrm{MPP}^{+}-$lesioned cultures (Fig. 3).

GM1 did not prevent the MPP+-induced loss of DA uptake activity. When GM1 was added before or together with MPP+ for $24 \mathrm{hr}$, there was no protection of DA uptake activity compared with cultures that were treated with $\mathrm{MPP}^{+}$alone (Table 1).

GM1 treatment elevated DA content in both control and 


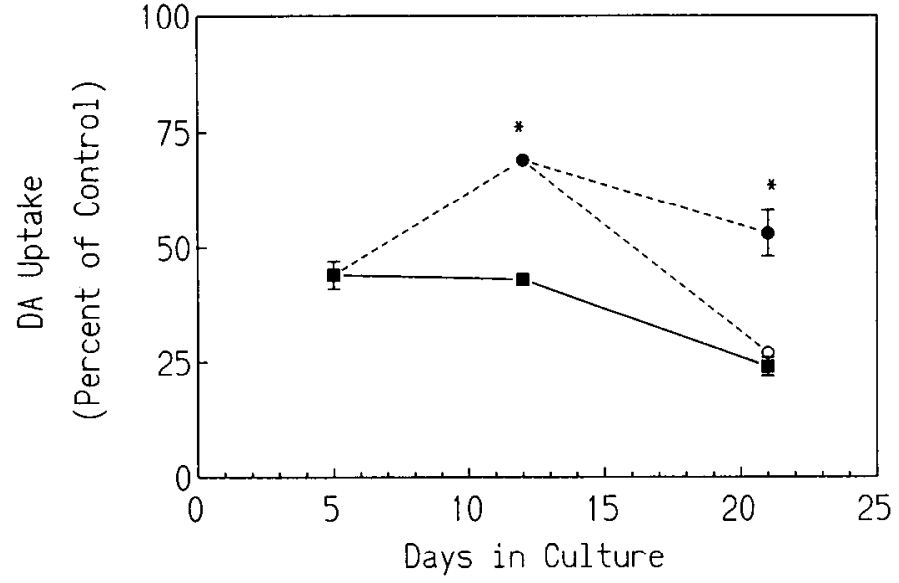

Figure 3. DA uptake by rat E15 mesencephalic cultures treated with $\mathrm{MPP}^{+}$alone, $\mathrm{MPP}^{+}$plus continuous treatment with GM1, or MPP+ plus limited treatment with GM1. Cultures were treated with MPP+, 3 $\mu \mathrm{M}$, on day 4 in culture for $24 \mathrm{hr}$ and then on day $5 \mathrm{MPP}^{+}$was removed and GM1, $0.5 \mu \mathrm{M}$, was added to two groups. The two groups were maintained with GM1 until day 12 in culture. Then GM1 was removed from one group (open circle) while GM1 was maintained in the other (solid circles). A comparison group consisted of $\mathrm{MPP}^{+}$treatment alone (solid squares). Data are presented as the mean \pm SEM for eight dishes. ${ }^{*}, p<0.05$ compared with $\mathrm{MPP}^{+}$alone.

$\mathrm{MPP}^{+}$-lesioned cultures. Only the lesioned cultures had elevated DOPAC content (Table 2).

We attempted to investigate $\mathrm{TH}$ activity in the cultures from the conversion of L-tyrosine to L-dopa with analysis by HPLC (Blank and Pike, 1976) and from the generation of ${ }^{3} \mathrm{H}_{2} \mathrm{O}$ during the conversion of ${ }^{3} \mathrm{H}$-tyrosine to dopa (Reinhard et al., 1986) but found both to be at the limits of sensitivity using the cultures and therefore inadequate for estimating enzyme activity. AAAD activity, however, was easily assayed in the cultures. Treatment with GM1 increased AAAD activity in control cultures (Table 2). Addition of $\mathrm{MPP}^{+}$decreased AAAD in the cultures and treatment with GM1 enhanced enzyme activity.

Table 1. GM1 does not prevent MPP ${ }^{+}$-induced reduction of DA uptake in embryonic mesencephalic cultures

\begin{tabular}{ll} 
Conditions & $\begin{array}{l}\text { DA uptake } \\
\text { (pmol/mg protein/min } \pm \text { SEM) }\end{array}$ \\
\hline $\begin{array}{l}\text { Contrast culture } \\
\text { Medium }\end{array}$ & $2.79 \pm 0.12$ \\
MPP & $1.17 \pm 0.04^{*}$ \\
Pretreatment & \\
GM1 & $2.90 \pm 0.06$ \\
GMl plus MPP & $1.10+0.06^{*}$ \\
Cotreatment & \\
GM1 & $2.96 \pm 0.05$ \\
GMl plus MPP & $1.09 \pm 0.04^{*}$
\end{tabular}

Mesencephalic cultures were prepared as follows: contrast culture, on day 4 in culture, MPP,$+ 3 \mu \mathrm{M}$, was added for $24 \mathrm{hr}$, the cultures were washed, and fresh medium was added for the remainder of the study; pretreatment, GM1, $0.5 \mu \mathrm{M}$, was added at plating and was present when MPP+ was added on day 4 for $24 \mathrm{hr}$; after washing fresh addition-free medium was added for the remainder of the study; cotreatment, on day 4 in culture both $\mathrm{MPP}^{+}$and $\mathrm{GM} 1$ were added for 24 $\mathrm{hr}$ and removed, and fresh addition-free medium was added for the remainder of the study. DA uptake was assessed on day 12 in cultures. $N=12$.

${ }^{*} p<0.05$ compared with culture medium alone or with GM1 treatment.
Table 2. GM1 enhances AAAD activity and DA and DOPAC content of mesencephalic cultures treated with MPP ${ }^{+}$

\begin{tabular}{lclc} 
& $\begin{array}{l}\text { AAAD activity } \\
\text { (pmol/mg } \\
\text { protein/ } \\
\text { 20 min } \pm \text { SEM) }\end{array}$ & $\begin{array}{l}\text { DA } \\
(\mathrm{pmol} / \mathrm{mg} \text { protein } \pm \text { SEM) }\end{array}$ \\
\hline Conditions & $3.9 \pm 0.2$ & $6.8 \pm 0.3$ & $11.8 \pm 0.5$ \\
Medium & $0.92 \pm 0.08^{*}$ & $9.5 \pm 0.6^{*}$ & $9.2 \pm 0.8$ \\
MPP+ & $4.4 \pm 0.2^{*}$ & $2.7 \pm 0.3^{*}$ & $4.2 \pm 0.5^{*}$ \\
GM1 & $1.6 \pm 0.1^{* *}$ & $5.2 \pm 0.5^{* *}$ & $9.5 \pm 0.2^{* *}$
\end{tabular}

Mesencephalic cultures were treated on day 4 in culture with $\mathrm{MPP}^{+}, 3 \mu \mathrm{M}$, for 24 hr. On day 5 fresh medium or GM1, $0.5 \mu \mathrm{M}$, was added where indicated. Fresh medium with GM 1 was added every $3 \mathrm{~d}$. On day 12 in culture AAAD activity and DA and DOPAC content were assayed. $N=5-10$.

${ }^{*} p<0.05$ compared with Medium.

** $p<0.05$ compared with MPP ${ }^{+}$.

About $1 \%$ of the cells in our cultures displayed TH-like immunoreactivity (Table 3). TH-immunopositive cells appeared to be bipolar or multipolar. Treatment with MPP ${ }^{+}$decreased the number of TH-immunopositive cells by about $60 \%$ without significantly diminishing the total number of phase-bright cells. After $\mathrm{MPP}^{+}$, there were fewer TH-positive cells. They were smaller and had fewer primary processes or no processes, and the observed processes were shorter (Fig. 4, Table 4). Treatment of control cultures with GM1 did not change the number of TH-immunopositive cells (Table 3 ), and they appeared similar to untreated control cells (Fig. 4, Table 4). Addition of GM1 to the $\mathrm{MPP}^{+}$-treated cultures resulted in a two- to threefold increase of TH-immunopositive cells (Table 3 ) to values found for control cultures, and the cells appeared essentially normal (Fig. 4). This is evident from quantitative image analysis of soma perimeter, the number of primary and secondary processes, and the length of the primary processes (Table 4).

To study the specificity of the response of the cultures to GM1, either antibodies to GM1 or the B subunit of cholera toxin was addcd concomitantly with GM1 to control and $\mathrm{MPP}^{+}$-treated cultures and DA uptake assayed. Both treatments reduced DA uptake in control cultures and prevented the augmentation of transporter activity by added GM1 (Table 5). Both treatments also prevented the DA uptake augmentation that occurs following treatment of MPP+-lesioned cultures with GM1. Neither treatment, however, altered DA uptake in MPP+-lesioned cultures without GM1.

Cultures were treated with Ara-C to reduce the ratio of glial cells to dopaminergic neurons (Table 6), and then the cultures were evaluated for DA uptake. Ara-C reduced dish protein by about $60 \%$, but DA uptake per dish was relatively unaffected; consequently, there was a rise of DA uptake per milligram of protein. Ara-C treatment had no discernable effect on the response of the cultures to GMI.

\section{Discussion}

MPTP administration results in the selective destruction of nigrostriatal dopaminergic neurons in humans and other species and therefore is used to induce experimental parkinsonism in animals. The biochemical, morphological, and behavioral deficits induced by MPTP in vivo can be reversed by administering GM1 ganglioside (Hadjiconstantinou et al., 1986, 1989a,b; Hadjiconstantinou and Neff, 1988, 1990; Janson et al., 1988; Weihmuller et al., 1988, 1989; Schneider et al., 1992). Improve- 

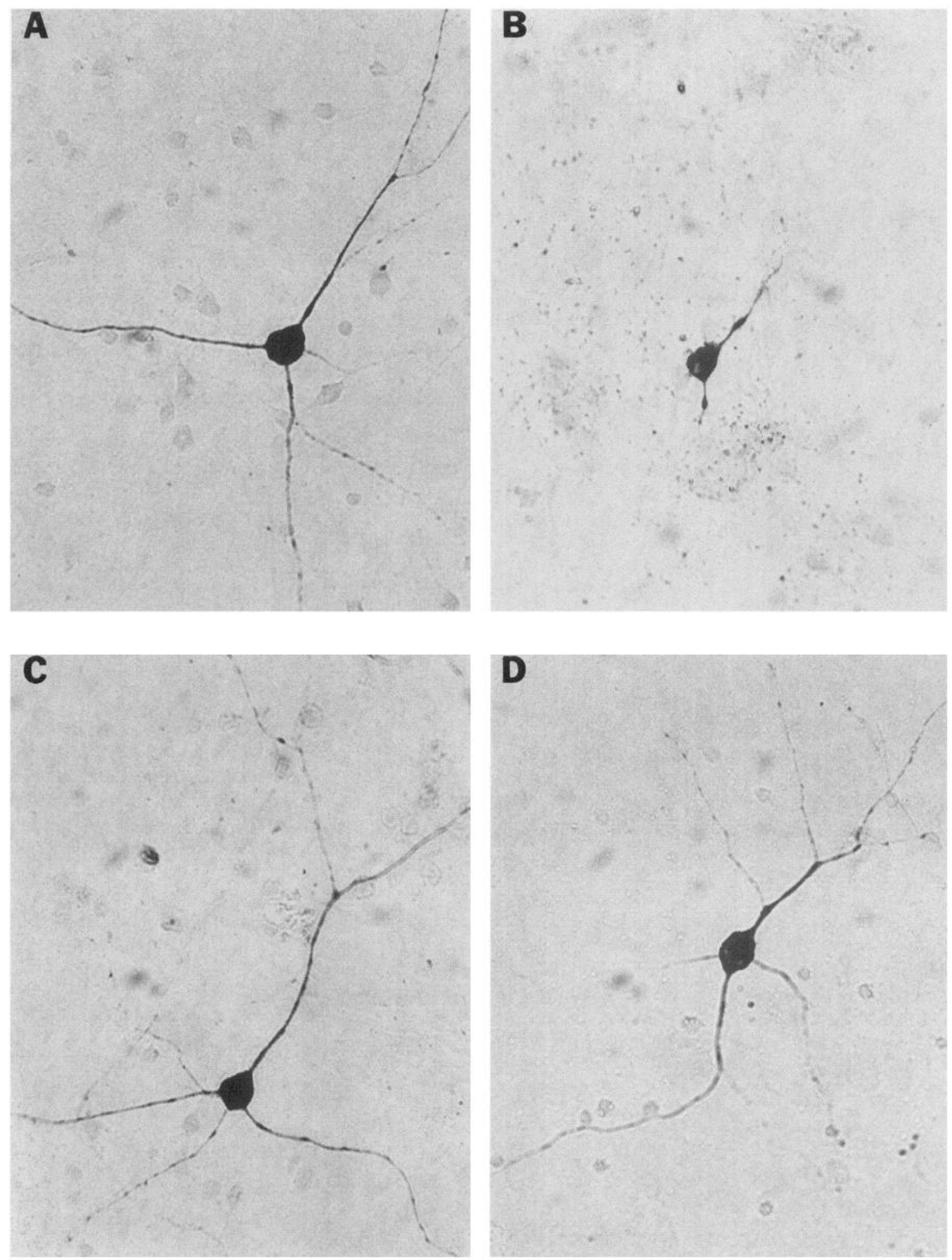

Figure 4. TH-immunopositive neurons in rat E15 ventral mesencephalic cultures after $12 \mathrm{~d}$ in vitro. A, Cells were maintained for $12 \mathrm{~d}$ in standard medium. $B$, After the fourth day in culture $\mathrm{MPP}^{+}, 3 \mu \mathrm{M}$, was added for $24 \mathrm{hr}$. The cultures were then maintained until day 12 in standard medium. $C$, Cultures were treated with $\mathrm{MPP}^{+}$as in $B$; however, GM1, $0.5 \mu \mathrm{M}$, was added to the cultures until assayed on day 12 . $D$, Control cultures were maintained from day 5 to day 12 in the presence of GM1, $0.5 \mu \mathrm{M}$.

ment is also observed after administering some mitogenic peptide growth factors such as epidermal growth factor (Hadjiconstantinou et al., 1991) and basic or acidic fibroblast growth factor (Date et al., 1990; Otto and Unsicker, 1990). These findings suggest that parkinsonism might be treated by administering these substances early in the course of the disease.

$\mathrm{MPP}^{+}$at a concentration of $3 \mu \mathrm{M}$ damaged dopaminergic mesencephalic neurons in culture when surveyed by biochem- 
Table 3. GM1 restores the number of TH-immunopositive cells in mesencephalic cultures treated with MPP+

\begin{tabular}{llcl} 
Conditions & $\begin{array}{l}\text { Total } \\
\text { cells } \pm \text { SEM } \\
\left(1 \times 10^{4}\right)\end{array}$ & $\begin{array}{l}\text { TH-positive cells } \\
\pm \text { SEM }\end{array}$ & $\begin{array}{l}\text { Percentage } \\
\text { of total } \\
\text { cells }\end{array}$ \\
\hline Medium & $8.3 \pm 0.1$ & $819 \pm 153$ & 0.99 \\
GM1 & $9.3 \pm 0.3$ & $1187 \pm 92$ & 1.27 \\
MPP $^{+}$ & $8.7 \pm 0.3$ & $335 \pm 35^{*}$ & 0.39 \\
MPP $^{+}$plus GM1 & $8.2 \pm 0.6$ & $828 \pm 51^{* *}$ & 1.00
\end{tabular}

Mesencephalic cells were grown on coverslips $(22 \times 22 \mathrm{~mm})$ and treated as described in Table 2 . On day 12 in culture the cells were fixed and the presence of TH was evaluated by immunohistochemistry. The number of cells on a coverslip was estimated by counting phase-bright cells in a superimposed counting frame and corrected for the size of the coverslip. $N=4-6$ coverslips.

${ }^{*} p<0.05$ compared with Medium.

${ }^{* *} p<0.05$ compared with MPP+

ical and morphological criteria. There was about a 40-60\% loss of DA uptake, DA and DOPAC content, AAAD activity, and TH-immunopositive cells when surveyed $7 \mathrm{~d}$ after MPP+ treatment. This observation is consistent with in vivo (Burns et al., 1983; Heikkila et al., 1984a) and in vitro (Mytilineou et al., 1985; Sanchez-Ramos et al., 1988) studies where there is evidence for selective destruction of dopaminergic neurons by $\mathrm{MPP}^{+}$. From an analysis of the TH-containing cells in the cultures, the progression of events appears to be loss of $\mathrm{TH}$-immunopositive processes with shrinkage of the soma and eventual loss of the soma image. Loss of DA uptake activity is consistent with the loss of terminal processes and therefore it can be used as an indirect biochemical index to evaluate nerve terminal status.

GM1 added to normal or lesioned cultures increased DA uptake in a concentration-dependent manner. $\mathrm{MPP}^{+}$-lesioned cells show enhanced uptake as early as $2 \mathrm{~d}$ after adding GM1, and uptake enhancement is maintained whereas control cultures show cnhanced uptake only on day 12 in culture. With the concentration of DA we used for studying DA uptake, the changes observed probably reflect an increased number of transporter sites. Indeed, Leon et al. (1988) found that GMl treatment increases the $V_{\max }$ for DA uptake in embryonic mesencephalic cultures. We found that GM1 was able to enhance AAAD activity as well as DA and DOPAC content in both control and $\mathrm{MPP}^{+}$-treated cultures. Apparently the effect of GM1 on the biochemistry of dopaminergic neurons in culture is broad and not a selective effect on DA uptake.

GM1 does not protect dopaminergic neurons in vivo when administered before MPTP (Hadjiconstantinou and Neff, 1988) and it does not protect mesencephalic dopaminergic neurons from destruction by $\mathrm{MPP}^{+}$in vitro. Our present finding that adding GM1 after a lesion has been initiated facilitates the recovery of all neurochemical parameters evaluated is consistent with the in vivo studies also (Hadjiconstantinou and Neff, 1988). In vivo early initiation of treatment is required for successful recovery as there appears to be a finite time after the insult when GMl is effective. Moreover, GMl treatment in vivo must be uninterrupted or recovery deteriorates (Hadjiconstantinou and Neff, 1988). Recovery of dopaminergic parameters also deteriorates in the mesencephalic cultures if GM1 is withdrawn.

Exogenous GM1 inserts into cell membranes (Toffano et al., 1980), and it induces differentiation and neurite outgrowth (Doherty et al., 1985; Skaper and Varon, 1985; Skaper et al., 1985; Mugnai and Culp, 1987). Antibodies to GM1 or the presence of the B subunit of cholera toxin modifies neurite outgrowth (Schwartz and Spirman, 1982; Spirman et al., 1982; Spoerri et al., 1988; Wu and Ledeen, 1991), demonstrating the importance of GM 1 for this response. We found that DA uptake activity was decreased in control GM1-untreated cultures if antibody to GM1 or the B subunit of cholera toxin was added, implying that DA uptake activity, and perhaps other dopaminergic parameters, is dependent either directly or indirectly on GM1. The GM1 content of serum is low (Dacremont, 1972); thus, the response to antibody or the $B$ subunit of cholera in the control untreated cultures is probably the consequence of their interaction with GM1 generated by the culture. Indeed, embryonic mesencephalic cultures can survive in a defined medium and added GM1 promotes DA uptake activity (Dal Toso et al., 1988). Both GM1 antibody and the B subunit prevented the GM1-induced increase of DA uptake in control and MPP+treated cultures, implying that a contaminant in the GM1 preparation is not responsible for the enhanced dopaminergic parameters.

Treatment with GM1 restored the number of TH-immunopositive cells and their morphology to near normal in cultures lesioned with MPP+ yet had little effect on control cultures not lesioned with MPP ${ }^{+}$. This may represent rescue by GM1 of the $\mathrm{MPP}^{+}$-injured neurons from eventual destruction. Alternatively, it is possible that $\mathrm{MPP}^{+}$reduces $\mathrm{TH}$ protein and thus neuron detectability by immunostaining and GM1 may upregulate $\mathrm{TH}$ expression restoring neuron detectability. This interpretation has been offered to explain the effect of NGF on the return of ChAT-immunopositive neurons following injury to cholinergic neurons (Varon et al., 1990). The fact that DA uptake does not

Table 4. GM1 restores the morphology of TH-immunopositive cells in mesencephalic cultures treated with MPP+

\begin{tabular}{lllll} 
Conditions & $\begin{array}{l}\text { Soma } \\
\text { perimeter } \\
(\mu \mathrm{m} \pm \mathrm{SEM})\end{array}$ & $\begin{array}{l}\text { Primary } \\
\text { process length } \\
(\mu \mathrm{m} \pm \mathrm{SEM})\end{array}$ & $\begin{array}{l}\text { Number of } \\
\text { primary processes } \\
(\text { mean } \pm \text { SEM) }\end{array}$ & $\begin{array}{l}\text { Number of } \\
\text { secondary processes } \\
(\text { mean } \pm \text { SEM) }\end{array}$ \\
\hline Medium & $56 \pm 3$ & $164 \pm 3$ & $2.8 \pm 0.17$ & $5.8 \pm 1$ \\
GM1 & $47 \pm 4$ & $180 \pm 8$ & $3.2 \pm 0.5$ & $5.8 \pm 1$ \\
MPP $^{+}$ & $37 \pm 1^{*}$ & $65 \pm 5^{*}$ & $1.8 \pm 0.14^{*}$ & $2.1 \pm 0.2^{*}$ \\
MPP $^{+}$plus GM1 & $46 \pm 1^{* *}$ & $176 \pm 5^{* *}$ & $3.0 \pm 0.2^{* *}$ & $5.7 \pm 0.4^{* *}$
\end{tabular}

Mesencephalic cells were grown on coverslips $(22 \times 22 \mathrm{~mm})$ and treated as described in Table 2 . On day 12 in culture the cells were fixed and TH-containing cells were visualized by immunostaining. Morphometric analysis was performed with an image analyzer (Magiscan). Data are the average for four different studies where 50 cells were counted per treatment.

$* p<0.05$ compared with Medium.

** $p<0.05$ compared with MPP+ 
Table 5. Cholera toxin B subunit or antibodies to GM1 prevent the GM1-induced increase of DA uptake in mesencephalic cultures treated with MPP $^{+}$

\begin{tabular}{lll} 
& \multicolumn{2}{l}{$\begin{array}{l}\text { DA uptake } \\
\text { (pmol/mg protein/15 min } \pm \mathrm{SEM})\end{array}$} \\
\cline { 2 - 3 } Conditions & Control & MPP \\
\hline Medium & $3.0 \pm 0.09$ & $1.7 \pm 0.07$ \\
GM1 & $3.5 \pm 0.2^{*}$ & $2.6 \pm 0.2^{*}$ \\
Ab-GM1 & $2.3 \pm 0.2$ & $1.7 \pm 0.2$ \\
CT-B & $2.0 \pm 0.2$ & $1.7 \pm 0.06$ \\
GM1 plus Ab-GM1 & $2.0 \pm 0.2$ & $1.5 \pm 0.2$ \\
GM1 plus B CT & $2.4 \pm 0.1$ & $1.6 \pm 0.2$
\end{tabular}

Mesencephalic cultures were treated on day 4 in culture with MPP,$+ 3 \mu \mathrm{M}$, for 24 hr. On day 5 the medium was changed and the cultures treated for the remainder of the study as indicated: medium alone, GM1 $0.5 \mu \mathrm{M}$, antibody to GM1 diluted $1: 100$, cholera toxin B subunit $5 \mu \mathrm{g} / \mathrm{ml}$, GM1 plus antibody to GM1, GM1 plus cholera toxin B subunit. DA uptake was assayed on day 12 in culture. $N=12$.

${ }^{*} p<0.05$ compared with all Control or MPP ${ }^{+}$groups, respectively. All MPP ${ }^{+}$. treated cultures were significantly different from Control cultures, $p<0.05 \mathrm{com}$ pared with other groups in the column

recover in the $\mathrm{MPP}^{+}$-treated cultures with time suggests that dopaminergic neurons are eventually lost. Therefore, we postulate that GM1 rescues moribund neurons, resulting in the return of dopaminergic parameters along with $\mathrm{TH}$ immunoreactivity.

Although the mechanism(s) for recovery of function after an injury is unknown, there is cvidence that GMl may have antineurotoxic and/or pro-neurotrophic actions. Neuronal insults are associated with excessive prolonged $\mathrm{Ca}^{2+}$ influx that is detrimental for neuronal survival (Rothman and Olney, 1987). In glutamate-induced neurotoxicity GM1 prevents the translocation of protein kinase $\mathrm{C}$ in injured neurons and may thereby limit intracellular $\mathrm{Ca}^{2+}$ increases (Vaccarino et al., 1987; Favaron et al., 1988; de Erausquin et al., 1990), thus protecting the neuron from delayed death (Manev et al., 1990). MPP+ increases glutamate in brain (Carboni et al., 1990) and NMDA receptor antagonists can prevent $\mathrm{MPP}^{+}$neurotoxicity (Turski et al., 1991). Pretreatment or cotreatment with GM1 together with $\mathrm{MPP}^{+}$or MPTP does not appear to prevent the toxic effects on dopaminergic neurons in culture or in vivo. However, early and continuous treatment with GMI after an MPIP or MPP+ lesion is required for a response. The early administration of GM1 after an insult may rescue neurons from delayed degeneration and death associated with elevated glutamate release. Brain-derived neurotrophic factor (BDNF) has been shown to prevent the MPP+ neurotoxicity in mesencephalic cultures by inducing glutathione synthetase activity (Spina et al., 1992).

In addition to possible anti-neurotoxic properties, GM1 may have restorative effects by modulating endogenous neurotrophic factor activity. Gangliosides modulate tyrosine kinase activity of trophic factor receptors, such as epidermal growth factor (Bremer et al., 1986), insulin growth factor-I, and platelet-derived growth factor (Hakomori et al., 1990). A tyrosine kinase receptor appears important for BDNF activity (Klein et al., 1991). Epidermal growth factor (Hadjiconstantinou et al., 1991) and BDNF promote recovery of mesencephalic neurons in culture (Hyman et al., 1991). Trophic factors for dopaminergic neurons are present in brain (Prochiantz et al., 1979, 1981; di Porzio et al., 1980), and added GM1 may facilitate their action on the injured neurons by modulating their synthesis, release. and/or recentor characteristics. For examnle. GMI has
Table 6. Enhanced DA uptake induced by GM1 in MPP + -treated mesencephalic cultures is not affected by prior treatment with Ara-C

\begin{tabular}{llll} 
& $\begin{array}{l}\text { DA uptake } \\
\text { (pmol/dish) }\end{array}$ & $\begin{array}{l}\text { DA uptake } \\
\text { (pmol/mg } \\
\text { protein) }\end{array}$ & $\begin{array}{l}\text { Protein } \\
(\mu \mathrm{g} / \mathrm{dish})\end{array}$ \\
\hline $\begin{array}{l}\text { Mixed cultures } \\
\text { Control }\end{array}$ & $1.5 \pm 0.1$ & $4.06 \pm 0.16$ & $346 \pm 20$ \\
MPP+ & $0.72 \pm 0.12^{*}$ & $2.11 \pm 0.14^{*}$ & $331 \pm 12$ \\
GM1 & $1.76 \pm 0.05$ & $4.4 \pm 0.2$ & $372 \pm 12$ \\
MPP + plus GM1 & $1.24 \pm 0.05^{* *}$ & $3.6 \pm 0.4^{* *}$ & $335 \pm 13$ \\
Neuronal cultures & & & \\
Control & $1.29 \pm 0.07$ & $8.6 \pm 0.9$ & $124 \pm 22$ \\
MPP+ & $0.67 \pm 0.09^{*}$ & $5.5 \pm 1.0^{*}$ & $147 \pm 15$ \\
GM1 & $1.39 \pm 0.05$ & $9.1 \pm 1.3$ & $157 \pm 8$ \\
MPP+ plus GM1 & $1.82 \pm 0.05^{* *}$ & $10.9 \pm 1.4^{* *}$ & $153 \pm 14$
\end{tabular}

Mesencephalic cultures were treated with Ara-C, $1.25 \mu \mathrm{M}$, for $24 \mathrm{hr}$ on day 3 in culture. On day 4 in culture they were washed and MPP+, $3 \mu \mathrm{M}$, added for $24 \mathrm{hr}$. On day 5 in culture GM1 was added, indicated in the table, and maintained for the remainder of the study. DA uptake was assayed on day 12 in culture. Data are presented as the mean \pm SEM for three or four dishes.

* $p<0.05$ compared with control.

** $p<0.05$ compared with MPP+.

a synergistic effect with NGF on brain cholinergic neurons (Cuello et al., 1989).

Enhanced DA uptake induced by epidermal growth factor is abolished by prior treatment of cultures with Ara-C, implying that the presence of glial cells is necessary for the response (Knusel et al., 1990). In contrast, Ara-C treatment did not alter the ability of GM1 to enhance DA uptake in cultures lesioned with $\mathrm{MPP}^{+}$, negating a role for glial cells in this response. Moreover, embryonic mesencephalic neurons in a defined culture medium show enhanced DA uptake when GM1 is included (Leon et al., 1988).

Based on reports in the literature and our studies with MPTP, neurotrophic peptides, and GM1, we postulate that the following events occur in the cultures lesioned with MPTP and treated with GM1. MPP+ is transported into the mesencephalic dopaminergic neurons and inhibits mitochondrial energy metabolism and all dependent biochemical events. Phenotypic expression is lost and the ncurons begin degenerating. Added GM1 inserts into membranes, limiting excessive $\mathrm{Ca}^{2+}$ influx and facilitating the action of neurotrophic factors present in the cultures, hence rescuing the cells and stimulating phenotypic expression, regeneration, and repair. Apparently, the rescued dopaminergic neurons are dependent on added GM1 as they lose their ability to take up DA if GM1 is removed. This observation is consistent with in vivo studies where dopaminergic parameters were found to deteriorate in MPTP-lesioned animals if GM1 treatment was terminated (Hadjiconstantinou and Neff, 1988).

In conclusion, $\mathrm{MPP}^{+}$induces selective destruction of dopaminergic neurons in rat embryonic mesencephalic cultures. There is loss of DA and DOPAC, AAAD activity, DA uptake, and TH-immunopositive cells. All of these parameters are partially restored by adding GM1 ganglioside to the cultures.

\section{References}

Beck KD, Knusel B, Pasinetti G, Michel PP, Zawadzka H, Goldstein M, Hefti F (1991) Tyrosine hydroxylase mRNA expression by dopaminergic neurons in culture: effect of 1-methyl-4-phenylpyridinium treatment I Neurnohem $57 \cdot 577-53$ ? 
Blank CL, Pike R (1976) A novel, inexpensive, and sensitive method for analysis of tyrosine hydroxylase activity in tissue samples. Life Sci 18:859-866.

Bremer EG, Schlessinger J, Hakomori SI (1986) Ganglioside-mediated modulation of cell growth. Specific effects of GM3 on tyrosine phosphorylation of the epidermal growth factor receptor. J Biol Chem 261: 2434-2440.

Burns SP, Chiueh CC, Markey SP, Ebert MH, Jacobowitz DM, Kopin IJ (1983) A primate model of parkinsonism: selective destruction of dopaminergic neurons in the pars compacta of the substantia nigra by $N$-methyl-1,2,3,6-tetrahydropyridine. Proc Natl Acad Sci USA 80: $4546-4550$.

Carboni S, Melis F, Pani L, Hadjiconstantinou M, Rosselti ZL (1990) The non-competitive NMDA-receptor antagonist MK-801 prevents the massive release of glutamate and aspartate from rat striatum induced by 1-methyl-4-phenylpyridinium (MPP $\left.{ }^{+}\right)$. Neurosci Lett 117: 129-133.

Cohen J, Hadjiconstantinou M, Neff NH (1983) Activation of dopamine-containing amacrine cells of retina: light-induced increase of acidic dopamine metabolites. Brain Res 260:125-127.

Cuello AC, Garofalo L, Kenigsberg RL, Maysinger D (1989) Gangliosides potentiate in vivo and in vitro effects of nerve growth factor on central cholinergic neurons. Proc Natl Acad Sci USA 86:2056-2060.

Dacremont G (1972) Ganglioside concentration in human plasma. Clin Chim Acta 37:449-454.

Dal Toso R, Giorgi O, Soranzo C, Kirschner G, Ferrari G, Favaron M, Benvegnu D, Presti D, Vicini S, Toffano G, Azzone GF, Leon A (1988) Development and survival of neurons in dissociated fetal mesencephalic serum-free cell cultures. I. Effects of cell density and of an adult mammalian striatal-derived neuronotrophic factor. J Neurosci 8:733-745.

Date I, Notter MFD, Felten SY, Felten DL (1990) MPTP-treated young mice but not aging mice show partial recovery of the nigrostriatal dopaminergic system by stereotaxic injection of acidic fibroblast growth factor (aFGF). Brain Res 526:156-160.

de Erausquin GA, Manev H, Guidotti A, Costa E, Brooker G (1990) Gangliosides normalize distorted single-cell intracellular free $\mathrm{Ca}^{2+}$ dynamics after toxic doses of glutamate in cercbellar granulc cells. Proc Natl Acad Sci USA 87:8017-8021.

di Porzio U, Daguet M-C, Glowinski J, Prochiantz A (1980) Effect of striatal cells on in vitro maturation of mesencephalic dopaminergic neurons grown in serum-free conditions. Nature 288:370-373.

Doherty P, Dickson JG, Flanigan TP, Leon A, Toffano G, Walsh FS (1985) Molecular specificity of ganglioside effects on neurite regeneration of sensory neurons in vitro. Neurosci Lett 62:193-198.

Favaron M, Manev H, Alho H, Bertolino M, Ferret B, Guidotti A, Costa E (1988) Gangliosides prevent glutamate and kainate neurotoxicity in primary neuronal cultures of neonatal rat cerebellum and cortex. Proc Natl Acad Sci USA 85:7351-7355.

Fishman PH (1986) Recent advances in identifying the functions of gangliosides. Chem Phys Lipids 42:137-151.

Friedman L, Mytilineou C (1987) The toxicity of MPTP to dopamine neurons in culture is reduced at high concentrations. Neurosci Lett 79:65-72.

Ghidoni R, Fiorilli A, Trinchera M, Venerando B, Chigorno V, Tettamanti G (1989) Uptake, cell penetration and metabolic processing of exogenous administered GM1 ganglioside in rat brain. Neurochem Int 15:455-465.

Hadjiconstantinou M, Neff NH (1988) Treatment with GM1 ganglioside restores striatal dopamine in the 1-methyl-4-phenyl-1,2,3,6tetrahydropyridine-treated mouse. J Neurochem 51:1190-1196.

Hadjiconstantinou M, Neff NH (1990) Differential recovery of dopamine synthetic enzymes following MPTP and the consequences of GM1 ganglioside treatment. Eur J Pharmacol 181:137-139.

Hadjiconstantinou M, Rossetti ZL, Paxton RC, Neff NH (1986) Administration of GM1 ganglioside restores the dopamine content in striatum after chronic treatment with MPTP. Neuropharmacology 25:1075-1077.

Hadjiconstantinou M, Rossetti ZL, Silvia C, Krajnc D, Neff NH (1988) Aromatic L-amino acid decarboxylase activity of the rat retina is modulated in vivo by environmental light. J Neurochem 51:15601564

Hadjiconstantinou M, Mariani AP, Neff NH (1989a) GM1 ganglioside-induced recovery of nigrostriatal dopaminergic neurons after MPTP: an immunohistochemical study. Brain Res 484:297-303.
Hadjiconstantinou M, Weihmuller FB, Neff NH (1989b) Treatment with GM1 ganglioside reverses dopamine D-2 receptor supersensitivity induced by the neurotoxin MPTP. Eur J Pharmacol 168:261264

Hadjiconstantinou M, Fitkin JG, Dalia A, Neff NH (1991) Epidermal growth factor enhances striatal dopaminergic parameters in the 1-methyl-4-phenyl-1,2,3,6-tetrahydropyridine-treated mouse. J Neurochem 57:479-482.

Hakomori S, Igarashi Y, Nojiri H, Bremer E, Hanai N, Nores GA (1990) Bioactive gangliosides modulating transmembrane signaling. In: Trophic factors and the nervous system (Horrocks LA, Neff NH, Yates AJ, Hadjiconstantinou M, eds), pp 135-153. New York: Raven.

Heikkila RE, Hess A, Duvoisin RC (1984a) Dopaminergic neurotoxicity of 1-methyl-4-phenyl-1,2,5,6-tetrahydropyridine in mice. Science 224:1451-1453.

Heikkila RE, Manzino L, Cabbat FS, Duvoisin RC (1984b) Protection against the dopaminergic neurotoxicity of 1-methyl-4-phenyl-1,2,5,6tetrahydropyridine by monoamine oxidase inhibitors. Nature 311 . 467-469.

Heikkila RE, Manzino L, Cabbat FS, Duvoisin RC (1985) Studies on the oxidation of the dopaminergic neurotoxin 1-methyl-4-phenyl1,2,5,6-tetrahydropyridine by monoamine oxidase B. J Neurochem 45:1049-1054.

Hyman C, Hofer M, Barde YA, Juhasz M, Yancopolos GD, Squinto SP, Lindsay RM (1991) BDNF in a neurotrophic factor for dopaminergic neurons of the substantia nigra. Nature 350:230-232.

Janson AM, Agnati LF, Fuxe K, Cintra A, Sundstrom E, Zini I, Toffano G, Goldstein M (1988) GM1 ganglioside protects against the 1-methyl-4-phenyl-1,2,3,6-tetrahydropyridine-induced degeneration of nigrostriatal dopamine neurons in the black mouse. Acta Physiol Scand 132:587-588.

Javitch JA, D'Amato RJ, Strittmatter SM, Snyder SH (1985) Parkinsonism-inducing neurotoxin, $N$-methyl-4-phenyl-1,2,3,6 tetrahydropyridine: uptake of the metabolite $N$-methyl-4-phenylpyridine by dopamine neurons explains selective toxicity. Proc Natl Acad Sci USA $82: 2173-2177$

Klein R, Nanduri V, Jing SA, Lamballe F, Tapley P, Bryant S, CordonCardo C, Jones KR, Reichardt LF, Barbacid M (1991) The trkB tyrosine protein kinase is a receptor for brain-derived neurotrophic factor and neurotrophin-3. Cell 66:395-403.

Knusel B, Michel PP, Schwaber JS, Hefti F (1990) Selective and nonselective stimulation of central cholinergic and dopaminergic development in vitro by nerve growth factor, basic fibroblast growth factor, epidermal growth factor, insulin, and the insulin-like growth factors I and II. J Neurosci 10:558-570.

Ledeen RW (1984) Biology of gangliosides: neuritogenic and neuronotrophic properties. J Neurosci Res 12:147-159.

Leon A, Dal Toso R, Presti D, Benvegnu D, Facci L, Kirschner G, Tettamanti G, Toffano G (1988) Development and survival of neurons in dissociated fetal mesencephalic serum-free cell cultures. II. Modulatory effects of gangliosides. J Neurosci 8:746-753

Lowry OH, Rosebrough NJ, Farr AL, Randall RJ (1951) Protein measurement with the Folin phenol reagent. J Biol Chem 193:265275 .

Manev H, Costa E, Wroblewski JT, Guidotti A (1990) Abusive stimulation of excitatory amino acid receptors: a strategy to limit neurotoxicity. FASEB J 4:2789-2797.

Mugnai G, Culp LA (1987) Cooperativity of ganglioside-dependent with protein-dependent substratum adhesion and neurite extension of human neuroblastoma cells. Exp Cell Res 169:328-344.

Mytilineou C, Cohen G, Heikkila RE (1985) 1-Methyl-4-phenylpyridine $\left(\mathrm{MPP}^{+}\right)$is toxic to mesencephalic dopamine neurons in culture. Neurosci Lett 57:19-24

Nicklas WJ, Vyas I, Heikkila RE (1985) Inhibition of NADH-linked oxidation in brain mitochondria by 1 -methyl-4-phenyl-pyridine, a metabolite of the neurotoxin, 1-methyl-4-phenyl-1,2,5,6-tetrahydropyridine. Life Sci 36:2503-2508.

Otto D, Unsicker K (1990) Basic FGF reverses chemical and morphological deficits in the nigrostriatal system of MPTP-treated mice. J Neurosci 10:1912-1921.

Prochiantz A, di Porzio U, Kato A, Berger B, Glowinski J (1979) In vitro maturation of mesencephalic dopaminergic neurons from mouse embryos is enhanced in presence of their striatal target cells. Proc Natl Acad Sci USA 76:5387-5391.

Prochiantz A, Daguet M-C, Herbet A, Glowinski J (1981) Specific 
stimulation of in vitro maturation of mesencephalic dopaminergic neurons by striatal membranes. Nature 293:570-572.

Reinhard JF Jr, Smith GK, Nichol CA (1986) A rapid and sensitive assay for tyrosine-3-monooxygenase based upon the release of ${ }^{3} \mathrm{H}_{2} \mathrm{O}$ and the adsorption of ${ }^{3}[\mathrm{H}]$-tyrosine by charcoal. Life Sci 39:21852189.

Rothman SM, Olney JW (1987) Excitotoxicity and the NMDA receptor. Trends Neurosci 7:299-302.

Sanchez-Ramos JR, Michel P, Weiner WJ, Hefti F (1988) Selective destruction of cultured dopaminergic neurons from fetal rat mesencephalon by 1-methyl-4-phenylpyridinium: cytochemical and morphological evidence. J Neurochem 50:1934-1944.

Schneider JS, Pope A, Simpson K, Taggart J, Smith MG, DiStefano L (1992) Recovery from experimental parkinsonism in primates with GM1 ganglioside treatment. Science 256:843-846.

Schwartz M, Spirman N (1982) Sprouting from chicken embryo dorsal root ganglia induced by nerve growth factor is specifically inhibited by affinity-purified anti-ganglioside antibodies. Proc Natl Acad Sci USA 79:6080-6083.

Singer TP, Ramsay RR, McKeown K, Trevor A, Castagnoli NE Jr (1988) Mechanism of the neurotoxicity of 1-methyl-4-phenylpyridinium (MPP+ ${ }^{+}$, the toxic bioactivation product of 1 -methyl-4-phenyl-1,2,3,6-tetrahydropyridine (MPTP). Toxicology 49:17-23.

Skaper SD, Varon S (1985) Ganglioside GM1 overcomes serum inhibition of neurite outgrowth. Int J Dev Neurosci 3:187-198.

Skaper SD, Katoh-Semba R, Varon S (1985) GM1 ganglioside accelerates neurite outgrowth from primary peripheral and central neurons under selected culture conditions. Brain Res 355:19-26.

Spina MB, Squinto SP, Miller J, Lindsay RM, Hyman C (1992) Brainderived neurotrophic factor protects dopamine neurons against 6-hydroxydopamine and $\mathrm{N}$-methyl-4-phenylpyridinium ion toxicity: involvement of the glutathione system. J Neurochem 59:99-106.
Spirman N, Sela B-A, Schwartz M (1982) Antiganglioside antibodies inhibit ncuritic outgrowth from regenerating goldfish retinal explants. J Neurochem 39:874-877.

Spoerri PE, Rapport MM, Mahadik SP, Roisen FJ (1988) Inhibition of conditioned media-mediated neuritogenesis of sensory ganglia by monoclonal antibodies to GM1 ganglioside. Dev Brain Res 41:7177.

Toffano G, Benvegnu D, Bonetti AC, Facci L, Leon A, Orlando P, Ghidoni R, Tettamanti G (1980) Interaction of GM1 ganglioside with crude rat brain neuronal membranes. J Neurochem 35:861-866.

Turski L, Bressler K, Rettig KJ, Loschmann PA, Wachtel H (1991) Protection of substantia nigra from MPP ${ }^{+}$neurotoxicity by $N$-methylD-aspartate antagonists [see comments]. Nature 349:414-418.

Vaccarino F, Guidotti A, Costa E (1987) Ganglioside inhibition of glutamate-mediated protein kinase $C$ translocation in primary cultures of cerebellar neurons. Proc Natl Acad Sci USA 84:8707-8711.

Varon S, Hagg T, Conner J, Fass B, Vahlsing HL, Manthorpe M (1990) Consequences to CNS cholinergic neurons of in vivo nerve growth factor administration. In: Trophic factors and the nervous system (Horrocks LA, Neff NH, Yates AJ, Hadjiconstantinou M, eds), pp 219-228. New York: Raven.

Weihmuller FB, Hadjiconstantinou M, Bruno JP, Neff NH (1988) Administration of GM1 ganglioside eliminates neuroleptic-induced sensorimotor deficits in MPTP-treated mice. Neurosci Lett 92:207-212.

Weihmuller FB, Hadjiconstantinou M, Bruno JP, Neff NH (1989) Continued administration of GM1 ganglioside is required to maintain recovery from neuroleptic-induced sensorimotor deficits in MPTPtreated mice. Life Sci 45:2495-2502.

Wu G, Ledeen RW (1991) Stimulation of neurite outgrowth in neuroblastoma cells by neuraminidase: putative role of $\mathrm{GM} 1$ ganglioside in differentiation. J Neurochem 56:95-104. 